\title{
BMJ Open Sleep and use of electronic devices in adolescence: results from a large population-based study
}

\author{
Mari Hysing, ${ }^{1}$ Ståle Pallesen, ${ }^{2,3}$ Kjell Morten Stormark, ${ }^{1}$ Reidar Jakobsen, ${ }^{1}$ \\ Astri J Lundervold, ${ }^{1,4}$ Børge Sivertsen ${ }^{5,6,7}$
}

To cite: Hysing M, Pallesen S, Stormark KM, et al. Sleep and use of electronic devices in adolescence: results from a large population-based study. BMJ Open 2015;5: e006748. doi:10.1136/ bmjopen-2014-006748

- Prepublication history for this paper is available online. To view these files please visit the journal online (http://dx.doi.org/10.1136/ bmjopen-2014-006748).

Received 26 September 2014 Revised 28 November 2014 Accepted 2 December 2014

\section{CrossMark}

For numbered affiliations see end of article.

Correspondence to Dr Mari Hysing; mari.hysing@uni.no

\section{ABSTRACT}

Objectives: Adolescents spend increasingly more time on electronic devices, and sleep deficiency rising in adolescents constitutes a major public health concern. The aim of the present study was to investigate daytime screen use and use of electronic devices before bedtime in relation to sleep.

Design: A large cross-sectional population-based survey study from 2012, the youth@hordaland study, in Hordaland County in Norway.

Setting: Cross-sectional general community-based study.

Participants: 9846 adolescents from three age cohorts aged 16-19. The main independent variables were type and frequency of electronic devices at bedtime and hours of screen-time during leisure time.

Outcomes: Sleep variables calculated based on selfreport including bedtime, rise time, time in bed, sleep duration, sleep onset latency and wake after sleep onset. Results: Adolescents spent a large amount of time during the day and at bedtime using electronic devices. Daytime and bedtime use of electronic devices were both related to sleep measures, with an increased risk of short sleep duration, long sleep onset latency and increased sleep deficiency. A dose-response relationship emerged between sleep duration and use of electronic devices, exemplified by the association between $\mathrm{PC}$ use and risk of less than $5 \mathrm{~h}$ of sleep (OR=2.70,95\% Cl 2.14 to 3.39 ), and comparable lower odds for $7-8 \mathrm{~h}$ of sleep $(\mathrm{OR}=1.64$, 95\% Cl 1.38 to 1.96).

Conclusions: Use of electronic devices is frequent in adolescence, during the day as well as at bedtime. The results demonstrate a negative relation between use of technology and sleep, suggesting that recommendations on healthy media use could include restrictions on electronic devices.

\section{BACKGROUND}

In the last decade, we have witnessed a sharp increase in the availability and use of electronic devices such as smart phones, video game consoles, television, audio players, computers and tablets. Owing to this, electronic devices have become an integral part of adolescent life, as exemplified by almost
Strengths and limitations of this study

- This study employed a large, well-defined population-based sample of adolescents.

- The data employed in this study are from a recent data collection.

- This study included several detailed measures of sleep patterns and sleep problems, as well as detailed measures of media use.

- The cross-sectional design of this study precluded any causal inference.

This sample had a limited age-range.

all American adolescents (97\%) reporting to have at least one electronic media device in their bedroom. ${ }^{1}$ In addition to the entertainment aspects, electronic devices play an important part in the social lives of adolescents. A more active, stimulating and social media use may, however, affect sleep in a negative way. ${ }^{2}$

Parallel with the increased use of electronic devices, there has been a shift towards poorer sleep over the past decades among adolescents. ${ }^{3}$ Recent epidemiological data on adolescent sleep shows that it is characterised, on average, by late bedtime, long sleep onset latency (SOL) and short sleep duration of approximately $6.5 \mathrm{~h}$ on weekdays, contributing to daily sleep deficiency of about 2 h. $^{4}$

The high rate of media use in adolescence may be one factor that is related to the short sleep duration and late bedtimes. TV use has consistently and inversely been associated with sleep duration, ${ }^{5}{ }^{6}$ as well as delayed bedtime and wake-up time in adolescents. ${ }^{7}$ A high level of computer use has been found to be related to sleep problems, ${ }^{8}$ reduced time in bed $^{9}{ }^{10}$ and increased SOL. ${ }^{11}$ Overall, electronic media use has been consistently linked with delayed bedtime and shortened sleep, according to a review of the literature. However, some shortcomings in 
the existing literature were noted in the review. Future studies were recommended to measure sleep by selfreport estimates of sleep parameters such as bedtime, SOL, time spent awake after sleep onset, wake-up time and rise time, each estimated separately for weekdays and weekend days. ${ }^{12}$ Newer technology, such as portable electronic devices, has also been recommended to be included in future studies on this topic. Related to this, many of the previous studies have restricted their investigation to only one or two electronic devices. ${ }^{2} 1013$ Whether the same pattern of sleep problems is present across type of electronic devices is thus uncertain.

The mechanisms behind the relationships between use of electronic media devices and sleep problems are not well established, but a theoretical model of the relationship has been proposed, ${ }^{12}$ suggesting several possible mechanisms. According to this model, media use may directly affect sleep by replacing it due to its time consuming nature, or it may interfere with sleep through increased psychophysiological arousal caused by the stimulating content of the material, or through bright light exposure inherent in most electronic media devices. ${ }^{12}$ Bright light may impact sleep in two ways: by delaying the circadian rhythm when exposure takes place in the evening ${ }^{14}$ and also by causing an immediate activation in itself. ${ }^{11} 15$ According to the aforementioned model, sleep may also be negatively impacted by electromagnetic radiation. ${ }^{12}$ Another proposed mechanism by which electronic media may impair sleep relates to physical discomfort, such as muscular pain and headache, which can be caused by prolonged media use (eg, computer games). ${ }^{16}$ Furthermore, repeated use of electronic media in bed or in the bedroom can reduce the sleep inducing properties of the latter two, as the bed and bedroom become associated with electronic media use. ${ }^{17}$

The present cross-sectional study will expand on the previous studies by taking a broad approach including measures of sleep duration, SOL and sleep deficiency, as well as including newer technological devices. Based on the presented literature on adolescent media use, we expected that the majority of adolescents would use electronic media devices at bedtime. Further, electronic media use was expected to be inversely related to sleep duration and positively related to SOL and sleep deficiency. Finally, we expected the association between sleep and media use to be similar across all devices/ platforms.

\section{METHODS}

\section{Study population}

In this cross-sectional population-based study, we used data from the youth@hordaland survey of adolescents in the county of Hordaland in Western Norway. All adolescent born from 1993 to 1995, and all students attending secondary education during spring 2012, were invited. The main aim of the survey was to assess prevalence of mental health problems and service use in adolescents. All questionnaires were piloted and refined in a single school in 2011 before including it in the youth@hordaland study. Data were collected during spring 2012. Adolescents in secondary education received information by email, and time during regular school hours was allocated for them to complete the questionnaire. The questionnaire was web-based, and a teacher was present to organise the data collection and to ensure confidentiality. Survey staff was available on a phone number for the adolescents as well as for school personnel for answering queries. Those not in school received information and could complete the questionnaire online.

\section{Sample}

A total of 19430 adolescents born between 1993 and 1995 were invited to participate, of which 10220 agreed, yielding a participation rate of $53 \%$. The mean age of those participating was 17 years, and the sample included more girls $(53.5 \% / \mathrm{n}=5252)$ than boys $(46.5 \% /$ $\mathrm{n}=4594)$. The majority $(97.9 \% / \mathrm{n}=9219)$ were high school students.

Sleep variables were checked for validity of answers, resulting in data from 374 participants being excluded due to obvious invalid responses. For example, when calculating sleep duration and sleep efficiency, individuals with negative values on these computed variables were excluded from further analyses. Thus, the total sample size in the current study was 9875 .

\section{Instruments}

\section{Use of electronic devices at bedtime}

As there are very few well-validated questionnaires assessing use of modern electronic devices, we chose to develop a new instrument assessing such use across a wide range of new electronic devices. This was done after a thorough review of the literature. Adolescents reported use of six different electronic media devices and on whether they used them in the bedroom during the last hour before they went to sleep. The phrasing of the question was: "How many of the listed electronic devices do you use in your bedroom the last hour before going to sleep?" Drag and drop function was incorporated as a feature of the web-based questionnaire. An image with corresponding description of the device was dragged and dropped to indicate use, and ranked by frequency of use with the most frequently used device in the top box, etc. The indicated devices comprised PC, cell phone, MP3 player, tablet, game console and TV. No information on the time frame was available, for example if the electronic devices had been used for shorter or longer periods of time (days, weeks or months).

\section{Screen time during daytime}

Time spent on screen-based activity was assessed by the following question: "Outside of school hours, how much time do you usually spend on the following on weekdays: 
(1) TV-games (PlayStation, Xbox, WII, etc), (2) PC games, (3) Internet chatting, (4) writing and reading emails, (5) using the PC for other purposes)?" The response alternatives were: 'no time', 'less than $1 / 2$ hour', ' $1 / 2$ hour to 1 hour', ' $2-3$ hours', ' 4 hours' and 'more than 4 hours'. A similar question has been used in the Health Behaviour in School-aged Children (HBSC) studies. ${ }^{18}$ A $2 \mathrm{~h}$ cut-off was used as most recommendations for screen-based activities restrict this to about $2 \mathrm{~h}$ per day, and this cut-off has also been used in previous relevant studies. ${ }^{19-21}$

\section{Sleep variables}

The adolescents' typical bedtimes and rise times were indicated in hours and minutes using a scroll down menu with 5 min intervals, and were reported separately for weekend and weekdays. Time in bed (TIB) was calculated by subtracting bedtime from rise time. Typical SOL and wake after sleep onset (WASO) were indicated in hours and minutes using a scroll down menu with 5 min intervals, and sleep duration was defined as TIB minus SOL and WASO. Sleep duration was split into 10 categories, and SOL was categorised as either more or less than $60 \mathrm{~min}$. Subjective sleep need (each individual's own perceived sleep need) was reported in hours and minutes on a scroll down menu with 5 min intervals, and the phrasing of the question was "How much sleep do you need to feel rested?" Sleep deficit was calculated separately for weekends and weekdays, subtracting total sleep duration from subjective sleep need. Weekday sleep deficiency is used in the present study, and was dichotomised into $<2 \mathrm{~h}$ and $\geq 2 \mathrm{~h}$. For more information on sleep variables and sleep patterns in the present study see ref. 4 .

\section{Statistics}

IBM SPSS Statistics 22 for Windows (SPSS Inc, Chicago, Illinois, USA) was used for all analyses. $\chi^{2}$ Tests were used to examine gender differences in use of electronic devices and daytime screen use. Independent sample $\mathrm{t}$ tests and $\chi^{2}$ tests were used to examine the associations between sleep duration, electronic devices and daytime screen use. Logistic regression analyses using SOL of more than $60 \mathrm{~min}$ and sleep deficiency as outcome variables were conducted for all electronic devices and daytime screen (exposure variables). Multinomial logistic regression analyses were conducted with short sleep duration as the outcome variable $(8-9 \mathrm{~h}$ as the reference category), and electronic devices and daytime screen as the exposure variables. To investigate whether ORs differed significantly between genders, we calculated the relative risk ratio. ${ }^{22}$ As these analyses yielded no significant gender differences, the results of the logistic regressions are presented without gender stratification.

\section{Ethics}

In accordance with the regulations from the REC and Norwegian health authorities, adolescents aged 16 years and older can make decisions regarding their own health, and may thus give consent themselves to participate in health studies. Parents/guardians have the right to be informed and, in the current study, all parents/ guardians received written information about the study in advance. If the adolescents decided to participate, they indicated if they wanted to participate in the study as a whole, or they could choose three options to specify their level of consent: (1) to complete the questionnaire, (2) obtain information from parent questionnaire (3) link data to national registries.

\section{RESULTS}

\section{Use of electronic devices before bedtime and daytime} screen time

The use of electronic devices stratified by gender is shown in figure 1. Most adolescents used an electronic device in the hour before going to sleep. Some gender differences emerged, with more boys using game consoles, whereas girls reported higher use of cell phones and Mp3 players $(\mathrm{p}<0.001)$.

The average number of hours of screen time stratified by gender is presented in figure 2. Girls reported significantly more online chatting and other PC use, while boys reported more console games and PC games (all $\mathrm{p}<0.001$ ).

\section{Electronic devices at bedtime and daytime screen use in relation to long SOL}

The ORs for reporting SOL of more than $60 \mathrm{~min}$ were calculated separately for each electronic device (table 1). Use of PC, cell phone, Mp3-player, tablet, game console and TV were all associated with increased odds of SOL of more than $60 \mathrm{~min}$.

Daytime screen use showed the same pattern. A total screen time after school hours for more than $4 \mathrm{~h}$ was related to long SOL (OR: 1.49, 95\% CI 1.36 to 1.64 ). When analyses were conducted separately for each electronic device, all daytime screen use over $2 \mathrm{~h}$ was significantly associated with long SOL (see table 1 ).

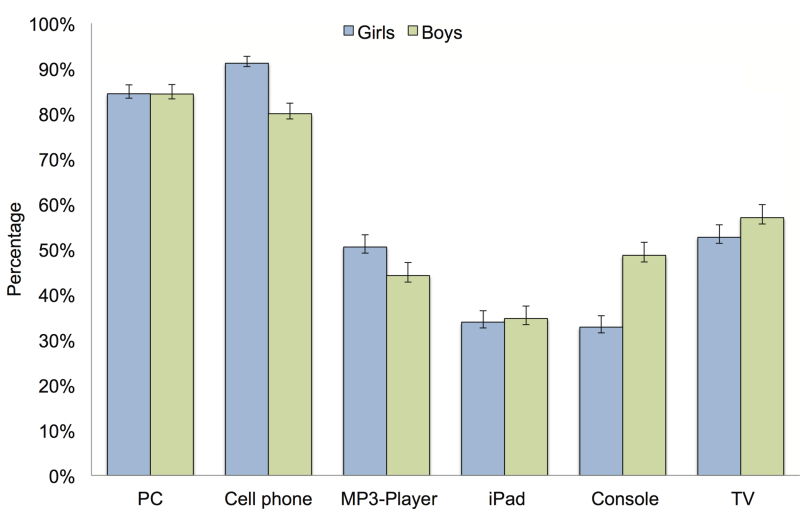

Figure 1 Use of electronic devices during the last hour before bedtime among girls and boys in the youth @ hordaland study ( $n=9846)$. Error bars represent $95 \%$ Cls. 


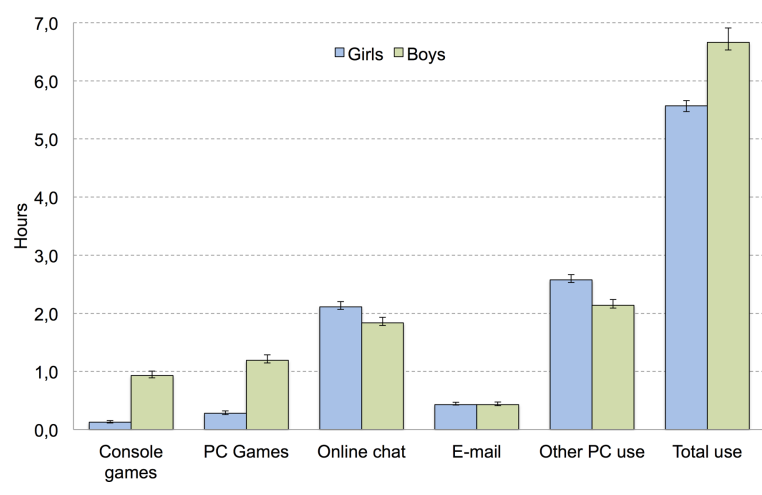

Figure 2 Average daytime screen use among girls and boys in the youth @ hordaland study $(\mathrm{n}=9846)$. Error bars represent $95 \%$ Cls.

\section{Electronic devices at bedtime and daytime screen use in relation to sleep deficit}

The odds for sleep deficiency of more than $2 \mathrm{~h}$ were calculated separately for each electronic device (table 1). Use of PC, cell phone, Mp3-player, game console and TV in the hour before going to sleep were all associated with increased odds of sleep deficiency.

Total daytime screen use after school of more than $4 \mathrm{~h}$ was positively related to sleep deficit. When analyses were conducted separately for different electronic devices, all instances of daytime screen use over $2 \mathrm{~h}$ were significantly associated with a sleep deficit.

\section{Electronic devices at bedtime and daytime screen use in relation to sleep duration}

Hours of daytime screen use are presented in figure 3. The odds for reporting short sleep duration (covering 4 different categories), with $8-9 \mathrm{~h}$ as the reference category, was calculated separately for each electronic device (table 2). A dose-response relationship emerged with the highest risk of short sleep duration under $5 \mathrm{~h}$, exemplified by the association between $\mathrm{PC}$ use and risk of less than $5 \mathrm{~h}$ of sleep (OR=2.70 95\% CI 2.14 to 3.39), while the risk for $7-8 \mathrm{~h}$ of sleep equalled an $\mathrm{OR}=1.64$ (95\% CI 1.38 to 1.96 ).

Daytime screen use showed a similar pattern. Total screen time above $4 \mathrm{~h}$ was associated with an increased risk of less than $5 \mathrm{~h}$ of sleep $(\mathrm{OR}=3.6495 \%$ CI 3.06 to 4.33 ), while the risk for $7-8 \mathrm{~h}$ of sleep was $\mathrm{OR}=1.29$ (95\% CI 1.12 to 1.49). See table 2 for details.

\section{Multitasking of electronic devices at bedtime}

The risk of SOL of more than 60 min was increased in adolescents using four devices or more compared with adolescents using only one device $(\mathrm{OR}=1.26$ (95\% CI 1.07 to 1.49$)$. The OR for sleep deficiency for multitasking 2-3 devices was 1.50 (95\% CI 1.26 to 1.79 ) and 4 or more devices was 1.75 (95\% CI 1.46 to 2.08 ), in comparison with using only 1 device. The ORs for sleeping less than $5 \mathrm{~h}$ among multitasking teens ranged from 2.2 to 2.8 (depending on number of used devices) compared with only one device. The corresponding OR ranges for sleeping $5-6 \mathrm{~h}, 6-7 \mathrm{~h}$ and $7-8 \mathrm{~h}$ were $1.8-2.4$, $1.9-2.1$ and $1.4-1.5$, respectively (all $\mathrm{p}<0.001$ compared with sleeping $8-9 \mathrm{~h}$ ).

\section{DISCUSSION}

In short, almost all adolescents reported using one or more electronic devices during the last hour before bedtime. Extensive use of these devices was significantly and positively associated with SOL and sleep deficiency, with an inverse dose-response relationship between sleep duration and media use.

The present study adds to the literature by showing that daytime and bedtime use of electronic devices across a range of platforms, including newer technology,

Table 1 Use of electronic devices in the last hour before bedtime and daytime screen use as risk factors for sleep onset latency (SOL) of 60 min or more, and sleep deficiency of $2 \mathrm{~h}$ or more in the youth @ hordaland study $(\mathrm{n}=9846) \dagger$

\begin{tabular}{|c|c|c|c|c|}
\hline & \multicolumn{2}{|c|}{ SOL ( $\geq 60 \mathrm{~min})$} & \multicolumn{2}{|c|}{ Sleep deficit ( $\geq 2 \mathrm{~h}$ ) } \\
\hline & OR & $95 \% \mathrm{Cl}$ & $\overline{\text { OR }}$ & $95 \% \mathrm{Cl}$ \\
\hline \multicolumn{5}{|c|}{ Electronic devices used in the last hour before bedtime } \\
\hline $\mathrm{PC}$ & $1.52^{\star \star \star}$ & 1.34 to 1.71 & $1.53^{\star \star \star}$ & 1.34 to 1.76 \\
\hline Cell phone & $1.48^{\star \star \star}$ & 1.30 to 1.68 & $1.35^{\star \star \star}$ & 1.17 to 1.55 \\
\hline MP3-player & $1.36^{\star \star \star}$ & 1.25 to 1.48 & $1.21^{\star \star \star}$ & 1.10 to 1.32 \\
\hline Tablet & $1.18^{\star \star \star}$ & 1.08 to 1.29 & $1.12^{\star}$ & 1.02 to 1.23 \\
\hline Console & $1.13^{\star \star \star}$ & 1.04 to 1.23 & $1.20^{\star \star \star}$ & 1.10 to 1.32 \\
\hline TV & $1.19^{\star \star \star}$ & 1.10 to 1.30 & $1.36^{\star \star \star}$ & 1.24 to 1.49 \\
\hline \multicolumn{5}{|l|}{ Daytime screen use } \\
\hline Total screen time $(4 \mathrm{~h}+)$ & $1.49^{\star \star \star}$ & 1.36 to 1.64 & $1.72^{\star \star \star}$ & 1.56 to 1.89 \\
\hline Console games $(2 \mathrm{~h}+)$ & $1.20^{\star}$ & 1.04 to 1.38 & $1.31^{\star \star \star}$ & 1.13 to 1.52 \\
\hline PC games $(2 \mathrm{~h}+)$ & $1.19^{\star \star}$ & 1.05 to 1.34 & $1.41^{\star \star \star}$ & 1.25 to 1.60 \\
\hline Online chat $(2 \mathrm{~h}+)$ & $1.43^{\star \star \star}$ & 1.31 to 1.56 & $1.87^{\star \star \star}$ & 1.70 to 2.05 \\
\hline Email $(2 \mathrm{~h}+)$ & $1.93^{\star \star \star}$ & 1.55 to 2.40 & $1.68^{\star \star \star}$ & 1.31 to 2.14 \\
\hline Other PC use $(2 \mathrm{~h}+)$ & $1.38^{\star \star \star}$ & 1.26 to 1.51 & $1.37^{\star \star \star}$ & 1.25 to 1.51 \\
\hline
\end{tabular}




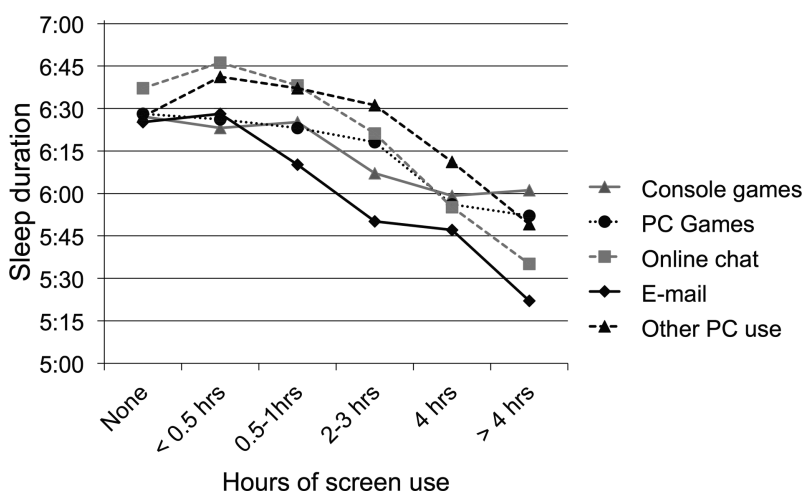

Figure 3 Sleep duration and hours of screen use among

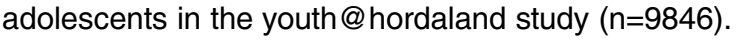

are related to several sleep parameters. While the frequency of use differed between the various devices, the relation between different types of electronic devices and sleep remained significant. This suggests that the established relationship between TV and sleep found in previous studies ${ }^{56}$ can be generalised to newer technology. The relation between sleep and PC-use that has been demonstrated in previous studies in relation to poor sleep ${ }^{8}$ and reduced time in bed ${ }^{9}{ }^{10}$ was further corroborated by the results of the present study, as PC was one of the most frequently used platforms, and also showed the highest risks for short sleep duration and sleep deficiency. Using multiple devices before bedtime was related to longer SOL and shorter sleep duration compared with using only one electronic device.

There are probably multiple pathways explaining the associations between sleep and electronic devices. Media use may directly affect sleep by replacing it due to its time consuming nature, or may interfere with sleep through increased psychophysiological arousal. Alternatively, the bright light exposure inherent in most electronic media devices ${ }^{12}$ may interfere with sleep by delaying the circadian rhythm when exposure takes place in the evening ${ }^{14}$ and/or by causing an immediate activation in itself. ${ }^{11} 15$

The relative importance of different devices is still a matter of discussion, although devices used for social communication have been proposed to have an especially negative effect on sleep. ${ }^{2}$ However, the present study showed few statistically significant differences between the electronic devices. Further, multitasking and the multifunctionality (eg, homework vs recreational use) of most platforms suggest that findings concerning the relationship between sleep and specific electronic devices and their type of use should be carefully interpreted.

The present study found that the associations between electronic media use and sleep were robust across the included sleep parameters, including SOL, sleep deficit and sleep duration, extending on the previous findings on the relationship between electronic media use and time in bed. ${ }^{9} 10$ The scarcity of similar studies makes the current findings hard to compare. In the 2010 review it was reported that two studies of adolescents assessed SOL, ${ }^{5} 23$ but after carefully inspecting the aforementioned papers we could not find support for this. While the present study found a higher risk of long SOL associated with electronic media use, the exact cut-offs for long SOL at different developmental levels have not been established. Long SOL is usually defined as $31 \mathrm{~min}$ or more in adults, ${ }^{24}$ but as adolescents may experience longer SOL due to biologically based delayed circadian rhythms occurring during puberty, ${ }^{25}$ we decided to use a cut-off of $60 \mathrm{~min}$.

Sleep need varies between individuals, and one can argue that adolescents with less need of sleep may spend more time on electronic devices than individuals with

Table 2 Use of electronic devices in the last hour before going to sleep and daytime screen use as risk factors for short sleep duration among girls and boys in the youth @ hordaland study $(n=9846) \dagger$

\begin{tabular}{|c|c|c|c|c|c|c|c|c|}
\hline & \multicolumn{2}{|l|}{$<5 \mathrm{~h}$} & \multicolumn{2}{|l|}{$5-6 h$} & \multicolumn{2}{|l|}{$6-7 \mathrm{~h}$} & \multicolumn{2}{|l|}{$7-8 \mathrm{~h}$} \\
\hline & $\overline{\text { OR }}$ & $95 \% \mathrm{Cl}$ & $\overline{\text { OR }}$ & $95 \% \mathrm{Cl}$ & $\overline{\text { OR }}$ & $95 \% \mathrm{Cl}$ & $\overline{\text { OR }}$ & $95 \% \mathrm{Cl}$ \\
\hline \multicolumn{9}{|c|}{ Electronic devices used in the last hour before bedtime } \\
\hline $\mathrm{PC}$ & $2.70^{\star \star *}$ & 2.14 to 3.39 & $2.69^{\star \star *}$ & 2.09 to 3.46 & $2.30^{\star * *}$ & 1.90 to 2.79 & $1.64^{\star * \star}$ & 1.38 to 1.96 \\
\hline Cell phone & $1.85^{\star * *}$ & 1.45 to 2.35 & $1.65^{\star \star *}$ & 1.28 to 2.13 & $1.75^{\star * \star}$ & 1.42 to 2.15 & $1.50^{\star \star *}$ & 1.24 to 1.83 \\
\hline MP3-player & $1.52^{\star \star \star}$ & 1.29 to 1.78 & $1.46^{\star \star \star}$ & 1.12 to 1.73 & $1.33^{\star \star \star}$ & 1.15 to 1.53 & $1.19^{\star}$ & 1.03 to 1.36 \\
\hline iPad or other tablet & $1.19^{*}$ & 1.01 to 1.41 & $1.29^{\star \star}$ & 1.09 to 1.54 & $1.18^{*}$ & 1.92 to 1.37 & 1.10 & 0.95 to 1.28 \\
\hline Console & $1.40^{\star \star \star}$ & 1.19 to 1.64 & $1.38^{\star \star *}$ & 1.17 to 1.64 & $1.27^{\star \star}$ & 1.09 to 1.47 & $1.17^{\star}$ & 1.01 to 1.35 \\
\hline TV & * & 1.25 & $1.44^{\star \star \star}$ & 1.22 & $1.35^{\star \star \star}$ & 1.1 & $1.16^{*}$ & 1.0 \\
\hline \multicolumn{9}{|l|}{ Daytime screen use } \\
\hline Total screen time $(4 \mathrm{~h}+)$ & $3.64^{\star \star \star}$ & 3.06 & $2.66^{\star \star \star}$ & 2.22 to 3.19 & $2.07^{\star \star \star}$ & 1.79 to 2.40 & $1.29^{\star \star \star}$ & 1.12 to 1.49 \\
\hline Console games $(2 \mathrm{~h}+)$ & $2.03^{\star \star \star}$ & 1.53 to 2.69 & $1.73^{\star \star \star}$ & 1.28 to 2.35 & $1.58^{\star \star}$ & 1.21 to 2.06 & 1.20 & 0.92 to 1.58 \\
\hline PC games $(2 \mathrm{~h}+)$ & $1.90^{\star * \star}$ & 1.51 to 2.38 & 1.22 & 0.95 to 1.58 & $1.39^{\star *}$ & 1.12 to 1.73 & 1.06 & 0.86 to 1.32 \\
\hline Online chat $(2 \mathrm{~h}+)$ & $3.58^{\star \star \star}$ & 3.03 to 4.24 & $2.79^{\star \star \star}$ & 2.33 to 3.33 & $1.98^{\star \star \star}$ & 1.70 to 2.30 & $1.31^{\star * \star}$ & 1.13 to 1.51 \\
\hline Email $(2 \mathrm{~h}+)$ & $3.28^{\star \star \star}$ & 2.07 to 5.16 & $2.42^{\star \star \star}$ & 1.48 to 3.95 & 1.34 & 0.84 to 2.14 & 1.14 & 0.72 to 1.82 \\
\hline Other PC use $(2 \mathrm{~h}+)$ & $2.06^{\star \star \star}$ & 1.74 to 2.42 & $2.04^{\star \star \star}$ & 1.71 to 2.44 & $1.54^{\star \star \star}$ & 1.33 to 1.78 & $1.21^{\star \star}$ & 1.05 to 1.39 \\
\hline
\end{tabular}

${ }^{*} \mathrm{p}<0.05 ;{ }^{* *} \mathrm{p}<0.01 ;{ }^{* * *} \mathrm{p}<0.001$.

†Reference: 8-9 h. 
more extensive sleep needs. The inclusion of perceived sleep need and sleep deficiency defined by subtracting the actual sleep from their perceived sleep allowed us to explore this further. In the current study, a sleep duration of 8-9 $\mathrm{h}$ was chosen as the reference category for all regression analyses, as this was the average sleep need reported by the adolescents, ${ }^{4}$ and also because this corresponds well with experts' recommended sleep need in this age group. ${ }^{25} \mathrm{~A}$ strong relationship between use of electronic devices and subjective sleep deficiency was present, thus indicating that use of electronic devices is related to sleeping less than what themselves and experts deem necessary. ${ }^{25}$

There are some methodological limitations of the present study that should be noted. First, the crosssectional design prevents us from drawing inferences about directionality. An indication of a causal relationship is the dose-response relationship between sleep duration and media use. In terms of a reverse causality, it might be that some adolescents actively use media and technology as a sleeping aid, ${ }^{26}$ or to counteract boredom when not being able to sleep. Most likely the relationship between poor sleep and electronic media use reflects a self-perpetuating cycle. Second, the phrasing of the questions assessing daytime and bedtime use of electronic devices does not rule out some overlap between the two items. For example, when adolescents report a total screen time use of $6+\mathrm{h}$, it is not unlikely that some adolescents include the last hour before going to sleep. Along the same lines, we had no information on the purpose of the screen time use, and as such we were not able to single out school-related work. Also, as the items assessing bedtime use were phrased to assess use in the bedroom only, we had no information on screen use in other rooms and how this might be related to sleep. In addition, it cannot be ruled out that some adolescents multitask and use electronic media in parallel with other activities. Third, the sleep measurements were solely based on self-reports, which renders the results susceptible to influence from the common method bias. ${ }^{27}$ Although self-reported sleep parameters, including SOL and WASO, typically differ from those obtained from objective assessments, ${ }^{28}$ recent studies have shown that self-report sleep assessments can be recommended for the characterisation of sleep parameters in clinical-based as well as population-based research. ${ }^{29}$ Also, the accuracy of self-reported SOL and WASO is generally better among adolescents than in older adults, ${ }^{30}$ and a study of young adolescents in Hong Kong recently found good agreement between actigraphy-measured and questionnaire-reported sleep durations. ${ }^{31}$ Fourth, there may be confounders, variables that are related to both sleep and media use, that were not assessed, for example, emotional and behavioural problems. Further, the clinical significance of the results may be discussed, as some of the increased risks were small in magnitude, and how much added functional significance these represent needs further exploration.
Also, attrition from the study could affect generalisability, with a response rate of about $53 \%$ and with adolescents in schools over-represented. The problem with non-participation in survey research seems unfortunately to be on the rise. ${ }^{32}$ Official data show that in $2012,92 \%$ of all adolescents in Norway aged 16-18 attended high school, ${ }^{33}$ compared with $98 \%$ in the current study. Based on previous research from the former waves of the Bergen Child Study (the same population as the current study), non-participants had more emotional and behavioural problems, albeit small in magnitude, in comparison with the participants. ${ }^{34}$ It is therefore likely that the prevalence of sleep problems may be underestimated in the current study. Finally, the cross-sectional design of the study restricts causal attributions, and prospective studies are still needed to disentangle the temporal relationship.

The assessment method may also have influenced the results. While the daytime screen use was based on a previous validated instrument, ${ }^{18}$ the questions used for the assessment of bedtime use of electronic devices were new. A broader scope compared with most previous studies, including questions about cell phones and Mp3-players as well as newer technology such as tablets, is a strength of the present study. Screen time use cannot be regarded as the absolute time spent in front of a screen, as other platforms may not be included, and there might be an overlap between daytime and bedtime use.

The recommendations for healthy media use given to parents and adolescents need updating, and age-specific guidelines regarding the quantity and timing of electronic media use should be developed and made known to the public. ${ }^{12}$ The current recommendation is not to have a TV in the bedroom. ${ }^{35}$ It seems, however, that there may be other electronic devices exerting the same negative influence on sleep, such as PCs and mobile phones. The results confirm recommendations for restricting media use in general. The combination of secular trends to impaired sleep, ${ }^{3}$ and the established relationship to health and school achievement, ${ }^{36}$ underscore the importance of prevention. The scope of the problem suggests that this is a public health issue and that primary prevention may be needed. Parent-set bedtimes have been shown to be related to good sleep hygiene in adolescents ${ }^{37}$ and an increased parental involvement in technology use could be a recommendation based on the findings, but this needs further evidence. While technology use may be a source of sleep deficiency, it may also serve as a medium of intervention, as internet-based interventions have proven to be effective and cost-efficient modes of treating sleep problems. ${ }^{38}$

\section{Author affiliations}

${ }^{1}$ Regional Centre for Child and Youth Mental Health and Child Welfare, Uni Research Health, Bergen, Norway

${ }^{2}$ Department of Psychosocial Science, University of Bergen, Bergen, Norway ${ }^{3}$ Norwegian Competence Center for Sleep Disorders, Haukeland University Hospital, Bergen, Norway 
${ }^{4}$ Department of Biological and Medical Psychology, University of Bergen, Bergen, Norway

${ }^{5}$ Division of Mental Health, Norwegian Institute of Public Health, Bergen, Norway

${ }^{6}$ Uni Research Health, Bergen, Norway

${ }^{7}$ Department of Psychiatry, Helse Fonna HF, Haugesund, Norway

Acknowledgements The authors would like to thank Regional Centre for Child and Youth Mental Health and Child Welfare at Uni Research Health for collecting the data and making the data available for this study. The authors would also like to thank the participants for their time and effort.

Contributors KMS, AJL, RJ and MH were involved in acquisition of data. MH and $\mathrm{BS}$ were responsible for conception and design of the study. BS and $\mathrm{MH}$ performed the analysis and interpretation of data. MH, BS and SP drafted the manuscript. KM, RJ and AJL gave critical revision of the manuscript for important intellectual content. KM and RJ obtained funding, and KM, RJ and AJL gave materialistic, technical or material support. MH and BS had full access to all data in the study and take responsibility for the integrity of the data and the accuracy of the data analysis.

Funding The youth@hordaland study was funded by Uni Research Health and Norwegian Directorate for Health and Social Affairs.

Competing interests None.

Ethics approval The Regional Committee for Medical and Health Research Ethics (REC) in Western Norway.

Provenance and peer review Not commissioned; externally peer reviewed.

Data sharing statement Data for research projects from the population-based youth@hordaland study may be made available on request from Regional Centre for Child and Youth Mental Health and Child Welfare, Uni Research Health, Bergen, Norway.

Open Access This is an Open Access article distributed in accordance with the Creative Commons Attribution Non Commercial (CC BY-NC 4.0) license, which permits others to distribute, remix, adapt, build upon this work noncommercially, and license their derivative works on different terms, provided the original work is properly cited and the use is non-commercial. See: http:// creativecommons.org/licenses/by-nc/4.0/

\section{REFERENCES}

1. National Sleep Foundation: Sleep In America Poll. http://wwwsleep foundationorg/article/sleep-america-polls/2006-teens-and-sleep. vol. 2006; 2006.

2. Van den Bulck J. Text messaging as a cause of sleep interruption in adolescents, evidence from a cross-sectional study. J Sleep Res 2003;12:263.

3. Pallesen S, Hetland J, Sivertsen B, et al. Time trends in sleep-onset difficulties among Norwegian adolescents: 1983-2005. Scand J Public Health 2008;36:889-95.

4. Hysing M, Pallesen S, Stormark KM, et al. Sleep patterns and insomnia among adolescents: a population-based study. J Sleep Res 2013:22:549-56.

5. Van den Bulck J. The effects of media on sleep. Adolesc Med State Art Rev 2010;21:418-29, vii.

6. Adam EK, Snell EK, Pendry P. Sleep timing and quantity in ecological and family context: a nationally representative time-diary study. J Fam Psychol 2007;21:4-19.

7. Thorleifsdottir B, Bjornsson JK, Benediktsdottir B, et al. Sleep and sleep habits from childhood to young adulthood over a 10-year period. J Psychosom Res 2002;53:529-37.

8. Dorofaeff TF, Denny S. Sleep and adolescence. Do New Zealand teenagers get enough? J Paediatr Child Health 2006;42:515-20.

9. Punamaki RL, Wallenius $\mathrm{M}$, Nygard $\mathrm{CH}$, et al. Use of information and communication technology (ICT) and perceived health in adolescence: the role of sleeping habits and waking-time tiredness. J Adolesc 2007;30:569-85.

10. Yen CF, Ko CH, Yen JY, et al. The multidimensional correlates associated with short nocturnal sleep duration and subjective insomnia among Taiwanese adolescents. Sleep 2008;31:1515-25.
11. Weaver E, Gradisar M, Dohnt H, et al. The effect of presleep videogame playing on adolescent sleep. J Clin Sleep Med 2010;6:184-9.

12. Cain N, Gradisar M. Electronic media use and sleep in school-aged children and adolescents: a review. Sleep Med 2010;11:735-42.

13. Weissbluth $\mathrm{M}$, Poncher J, Given $\mathrm{G}$, et al. Sleep duration and television viewing. J Pediatr 1981;99:486-8.

14. Khalsa SB, Jewett ME, Cajochen $\mathrm{C}$, et al. A phase response curve to single bright light pulses in human subjects. J Physiol 2003;549:945-52.

15. Campbell SS, Dijk DJ, Boulos Z, et al. Light treatment for sleep disorders: consensus report. III. Alerting and activating effects. J Biol Rhythms 1995;10:129-32.

16. Thomee S, Dellve L, Harenstam A, et al. Perceived connections between information and communication technology use and mental symptoms among young adults - a qualitative study. BMC Public Health 2010;10:66.

17. Hauri P, Fisher J. Persistent psychophysiologic (learned) insomnia. Sleep 1986;9:38-53.

18. Melkevik O, Torsheim T, lannotti RJ, et al. Is spending time in screen-based sedentary behaviors associated with less physical activity: a cross national investigation. Int J Behav Nutr Phys Act 2010;7:46

19. Bar-on ME. The effects of television on child health: implications and recommendations. Arch Dis Child 2000;83:289-92.

20. Owens J, Maxim R, McGuinn M, et al. Television-viewing habits and sleep disturbance in school children. Pediatrics 1999;104:e27.

21. Alexandru G, Michikazu S, Shimako H, et al. Epidemiological aspects of self-reported sleep onset latency in Japanese junior high school children. J Sleep Res 2006;15:266-75.

22. Altman DG, Bland JM. Interaction revisited: the difference between two estimates. BMJ 2003;326:219.

23. Johnson JG, Cohen $\mathrm{P}$, Kasen $\mathrm{S}$, et al. Association between television viewing and sleep problems during adolescence and early adulthood. Arch Pediatr Adolesc Med 2004;158:562-8.

24. Lichstein KL, Durrence HH, Taylor DJ, et al. Quantitative criteria for insomnia. Behav Res Ther 2003;41:427-45.

25. Carskadon MA, Harvey K, Duke $\mathrm{P}$, et al. Pubertal changes in daytime sleepiness. Sleep 1980;2:453-60

26. Eggermont S, Van den Bulck J. Nodding off or switching off? The use of popular media as a sleep aid in secondary-school children. $J$ Paediatr Child Health 2006;42:428-33.

27. Podsakoff PM, MacKenzie SB, Lee JY, et al. Common method biases in behavioral research: a critical review of the literature and recommended remedies. J Appl Psychol 2003;88:879-903.

28. Lauderdale DS, Knutson KL, Yan LL, et al. Self-reported and measured sleep duration: how similar are they? Epidemiology 2008;19:838-45.

29. Zinkhan M, Berger K, Hense S, et al. Agreement of different methods for assessing sleep characteristics: a comparison of two actigraphs, wrist and hip placement, and self-report with polysomnography. Sleep Med 2014;15:1107-14.

30. Dillon HR, Lichstein KL, Dautovich ND, et al. Variability in selfreported normal sleep across the adult age span. J Gerontol B Psychol Sci Soc Sci 2014;70:46-56.

31. Kong AP, Wing YK, Choi KC, et al. Associations of sleep duration with obesity and serum lipid profile in children and adolescents. Sleep Med 2011;12:659-65.

32. Morton SMB, Bandara DK, Robinson EM, et al. In the 21st century what is an acceptable response rate? Aust $N Z \mathrm{~J}$ Public Health 2012;36:106-8.

33. The Directorate of Integration and Diversity (IMDi): [education participation in high schools]. http://www.imdi.no/no/Fakta-ogstatistikk/Fakta-og-statistikk/Utdanning/?tab=chr; 2012.

34. Stormark KM, Heiervang E, Heimann M, et al. Predicting nonresponse bias from teacher ratings of mental health problems in primary school children. J Abnorm Child Psychol 2008;36:411-19.

35. Gentile DA, Oberg C, Sherwood NE, et al. Well-child visits in the video age: pediatricians and the American Academy of Pediatrics' guidelines for children's media use. Pediatrics 2004;114:1235-41.

36. Dewald JF, Meijer AM, Oort FJ, et al. The influence of sleep quality, sleep duration and sleepiness on school performance in children and adolescents: a meta-analytic review. Sleep Med Rev 2010;14:179-89.

37. Short MA, Gradisar M, Wright $\mathrm{H}$, et al. Time for bed: parent-set bedtimes associated with improved sleep and daytime functioning in adolescents. Sleep 2011;34:797-800.

38. Sivertsen B, Vedaa O, Nordgreen T. The future of insomnia treatment-the challenge of implementation. Sleep 2013;36:303-4. 